\title{
Work-Life of Indian Railway's Drivers (Loco-Pilots)
}

\author{
Rajesh Ranjan ${ }^{1}$, Dr. T. Prasad ${ }^{2}$ \\ $I^{\text {st }}$ (Doctoral Research Scholar, National Institute of Industrial Engineering, India) \\ $2^{\text {nd }}$ (Professor, National Institute of Industrial Engineering, Mumbai, India)
}

\begin{abstract}
Railways' Drivers / Loco-Pilots are the most important person in executing the huge task of transporting nearly 25 Million passengers and more than 2.8 Million Tons of freight daily with the help of 2,29,381 wagons, 59,713 coaches and more than 9,213 locomotive engines of various kinds(www.Indian railways, Wikipedia).To transport 25 million passengers and millions of tons of freight and that too with taking care of both the traveler's convenience and safety is not a mean task, the driver on whose sincerity the journey of a train depends. If he is not capable of carrying his responsibilities then the efforts of the other employees go waste, in this sense we can say that he is the most important person of the railways.

The job of a Railway Driver demands hard work and great presence of mind along with courage to handle diverse conditions. For this one should have discipline, patience, responsibility, punctuality, commitment, courage and above all self-confidence. The job requires lots of hard work, stamina, alertness of mind, adaptability to follow difficult time schedules too. But the main and remarkable, highly appreciable role of Railway drivers is the only who works with full honesty, in day \& night, in heavy cold, hot \& Rainy weather. For Railways' drivers operating on long distance routes, overnight stays in various locations will be necessary. Furthermore, it can be stressful, as delays and hazards on the track are not uncommon. His cab of the train should be relatively comfortable but it may be quite cold, hot and noisy.
\end{abstract}

Keywords: Railway driver, working conditions.

\section{Introduction}

It is 24th of December-2012. I was going to Patna from Mumbai by train (Rajendra Nagar Exp.). I seat on my birth. By looking at co-travelers, I felt my journey will going to be comfortable. We started gossiping with each other. Out of them one passenger was behaving very interesting. So, I was interacting with him and make a personal gossiping. During the gossiping, I know his name Pintu Kumar (name changed), age-32 years, working as a Railway driver and posted in Chhapra Junction under NER (North East Railway, H.Q.-Gorakhpur). So, I make a personal attention and try to understand the working conditions of him as an Indian Railways' drivers.

\section{Overview/Analysis}

I started gossiping and told him you are (as a Railway Driver) most important person for Indian Railways' as well as for passengers. Because crores of passengers' life in your hand. But he says, no sir! We are not valuable persons for IR and IR not treated very well. I concentrate him, because I feel, he is not fully satisfied with his job as a Railway Driver. So, I inquired more about the facilities provided by the Indian Railways (IR). And also try to understand his working conditions. I ask many questions and he respond properly. He gives details information regarding Indian Railways' Drivers.

Railways' Drivers / Loco-Pilots are the most important person in executing the huge task of transporting nearly 25 Million passengers and more than 2.8 Million Tons of freight daily with the help of 2,29,381 wagons, 59,713 coaches and more than 9,213 locomotive engines of various kinds(www.Indian railways, Wikipedia).To transport 25 million passengers and millions of tons of freight and that too with taking care of both the traveler's convenience and safety is not a mean task, the driver on whose sincerity the journey of a train depends. If he is not capable of carrying his responsibilities then the efforts of the other employees go waste, in this sense we can say that he is the most important person of the railways. Thus Railway Driver is one of the most important posts in the railway staff. He is the person (along with the Guard) in charge of the train. Driver is also responsible to carry the train safely to its destination. For instance, in some cases if the train breaks down, or if a signal is defective the driver must consult the guard on how to proceed but ultimately it is the driver whose presence of mind, calmness, responsibility towards his work and above all his co-ordination with the guard is necessary to do the job in tough conditions. We can say that he is the person who shoulders the responsibility along with the Guard of taking the train from one destination to other safely. In that sense he is one of the most important employees in the Railway. One has to be really dedicated and hardworking to handle 
this work. Railway drivers playing a key role in Indian Railway's safe \& punctual running of trains with security and productivity (www.indian railway driver information, 2012).

\subsection{Important Features of Indian Railways' Drivers/Loco Pilots}

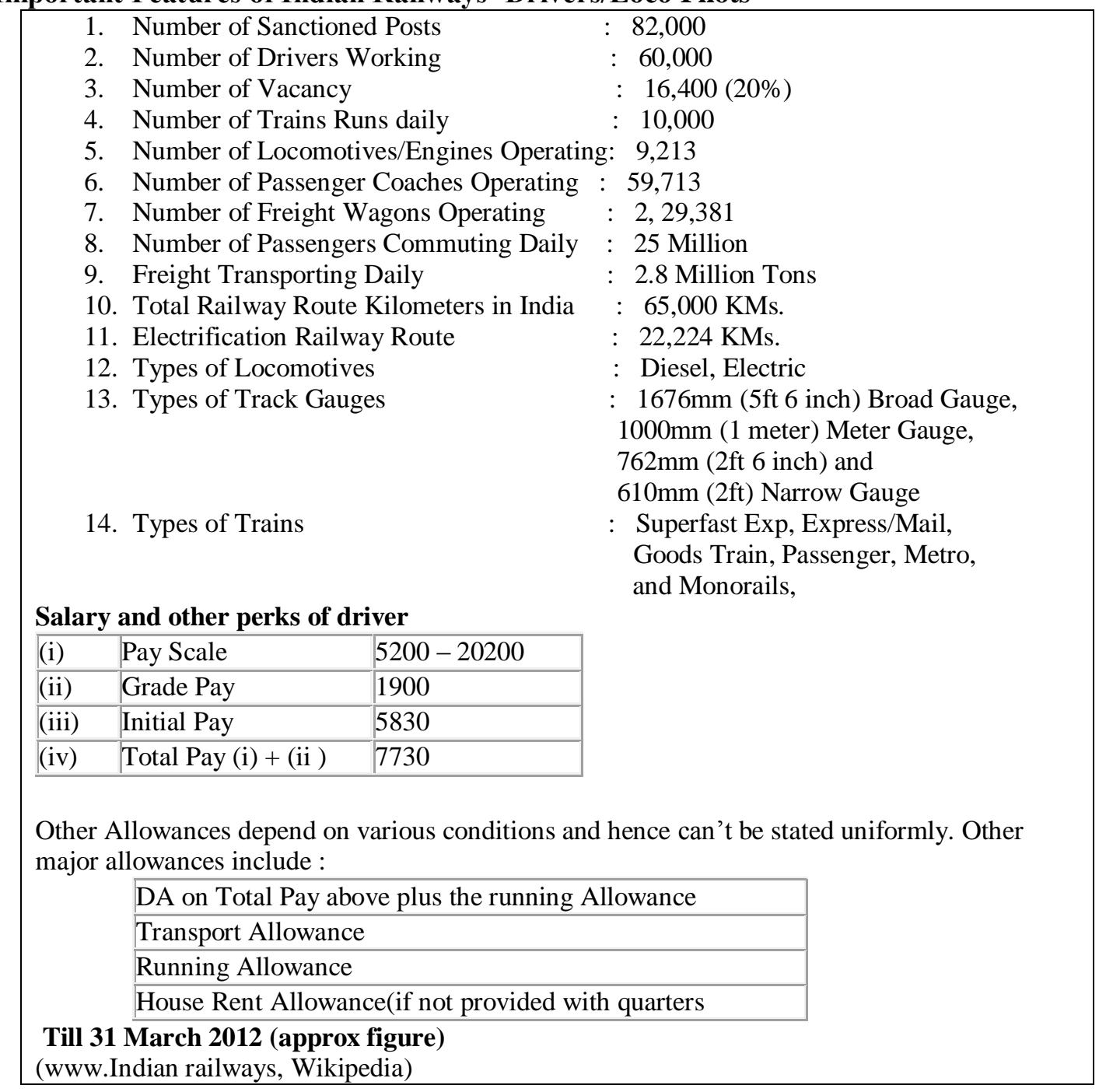

\section{Job Description of Indian Railways Drivers/Loco- Pilots}

\subsection{Objectives of the job:}

Railways' Drivers / Loco-Pilots are the most important person in executing the huge task of transporting nearly 25 Million passengers and more than 2.8 Million Tons of freight daily with the help of 2,29,381 wagons, 59,713 coaches and more than 9,213 locomotive engines of various kinds. To transport 25 million passengers and millions of tons of freight and that too with taking care of both the traveler's convenience and safety is not a mean task, the driver on whose sincerity the journey of a train depends. (www.Indian railways, Wikipedia).

\subsection{Work to be performed}

Driver is responsible to carry the train safely to its destination. Railway drivers playing a key role in Indian Railway's safe \& punctual running of trains with security and productivity (www.indian railway driver information, 2012).

\subsection{Railways' drivers need to possess the following skills}

I. Good mechanical knowledge.

II. Good hands-eye co-ordination.

III. The ability to concentrate for long periods of time.

IV. Physical stamina. 
V. Good memory.

VI. Flexibility.

VII. Excellent awareness of health and safety regulations and emergency procedures.

VIII. A responsible attitude.

IX. Good judgment and decision-making skills.

X. Reliability.

\subsection{Responsibilities}

The job of a Railway Driver demands hard work and great presence of mind along with courage to handle diverse conditions. For this one should have discipline, patience, responsibility, punctuality, commitment, courage and above all self-confidence. The job requires lots of hard work, stamina, alertness of mind, adaptability to follow difficult time schedules too. But the main and remarkable, highly appreciable role of Railway drivers is the only who works with full honesty, in day \& night, in heavy cold, hot \& Rainy weather (www.indian railway driver information, 2012).

\subsection{The typical tasks undertaken by Railways' drivers are}

i. Before starting the train/locomotive read safety circulars, safety bulletin, technical circulars, driver instruction, caution order, and divisional circulars.

ii. Before starting the train/locomotive read the caution order carefully in which sectional track work progress with temporary speed restriction is mention.

iii. Before starting the train/locomotive check the repair book of loco about any remark for any locomotive trouble.

iv. Before starting the train/locomotive check the oil level (diesel, lube oil, compressor oil in case of diesel locomotive and transformer oil, GR oil, compressor oil, exhauster oil in case of electric locomotive) and time to time during the run (One time during about 100 kilometers, it depends on drivers' mind).

v. After coupling with the train check brake pipe pressure continuity test with guard.

vi. After getting departure signal, loco pilot must start the train and run the train as per the aspect of station signals.

vii. Loco pilot must have sharp look out. While on run he must observe all permanent \& temporary speed restrictions.

viii. Loco pilot must always ready to notice:-

a. Any track defect through jerk or lurch,

b. Any unusual with self or others train. He must be mentally prepared for precautionary remedies as per the general \& subsidiary rules and accident manual directives. It itself is sufficient to mental stress of loco pilots.

ix. Checking the engine and general state of the train prior to starting each journey.

x. Maintaining an awareness of track conditions and weather conditions.

xi. Following signals (Averagely there are signals after every 1.5 Kilometer distance).

xii. Following safety regulations at all times.

xiii. Keeping the train under control and at the appropriate speed at all times.

xiv. Keeping control of instruments including brakes.

xv. Maintaining an awareness of emergency procedures.

xvi. Stopping the train at the appropriate stops on each schedule.

xvii. Keeping a record of any Problems.

(Singh Ravi Kant, 2008).

\subsection{Working Conditions}

For Railways' drivers operating on long distance routes, overnight stays in various locations will be necessary. Furthermore, it can be stressful, as delays and hazards on the track are not uncommon. His cab of the train should be relatively comfortable but it may be quite cold, hot and noisy (Singh Ravi Kant, 2008).

\subsection{Relationship of the job to other jobs}

I. Nature of duty of loco running staff remains unchanged as compared to all other category of Indian railway. For Ex. Previously ticket reservations were manually prepared maintain record by reservation clerk. And after completion of duty they have to count no. of selling of tickets \& amount manually. Now they are doing all the reservations on computer and they are getting full data about no. of reservations and amount of the tickets on computer in a short time. Similarly station masters signals operating panel system instead previous lever operated track points \& signals. Pathway inspector now checking track through ultrasonic machine instead of previous manual check. Now they have TTM (TRACK TESTING 
MACHINE) for track testing \& lifting \& packing. Whereas in loco running staff duty, the duties of running staff which was perform in the previous days, still remain same in present modernized railway (Singh Ravi Kant, 2008).

II. There is no any such category, in Govt. transport organization other than loco running staff of Indian railway, who have A-1 medical standard + super psycho \& classified as class H-I. Airplane/Air Force Pilots, Ship Captain are not classified as class H-I. Their pay should not be fixing as per the nature of duty, considering the risk factor, required medical standard, number of days \& duty hours performing duty (Singh Ravi Kant, 2008).

III. Staff Nurses get Rs.11, 940 for uniform and washing allowance annually, but Loco- Pilot gets only Rs. 438.50 annually (FIRE Quartly Magazine, Aug.2012).

\section{Job Specifications of Indian Railways Drivers/Loco- Pilots}

\subsection{Eligibility for Assistant Loco-Pilot/Railway Drivers}

4.1.1 Steps After clearing the Written Examination (conducted by RRB) followed by Aptitude Test after this Medical test and finally Document verification.

4.1.2 Age Minimum age of the aspiring candidate should be 18 years and maximum age limit is 30 years.

4.1.3 Educational Qualifications Because of vast advanced Technological changes and fast movement of train operation Railway required the group of high leveled Technical staff for train operation. Hence Railway started recruitment of literate staff in 1962 through RRB. And from last 20 years, the Railway demanding ITI or technical diploma like Diploma in mechanical/ electrical/ electronic engg.etc. for the post of Assistant Loco Pilot/Railway Drivers (Singh Ravi Kant, 2008).

4.1.4 Medical Standards Candidate must have high leveled medical standard which is no other category required so far. Loco running men/railway drivers must have the highest standard of medical fitness in medical 'A' (As it meant for Airplane Pilots). This medical standard has to maintain from the period of joining and up to the end of carrier as Railway driver. A) Each eye vision must be perfect. B) Each ear must be clear for hearing. C) X-ray for chest is clear. D) ECG for heart etc functioning normal. E) Blood \& Urine tests for sugar Nil. F) Physical fitness of the body must be perfect. G) Ishihara test free from color blind free. H) Blood pressure must be normal. The same medical checkup, the Railway drivers must have to pass after every periodical gap of 4 years up to the age of 45 years. From 45 years age to 55 years age, periodical medical examination in the same above manner is conducted once in 2 years. And from 55 years age up to 60 years age PME is conducted once in year. And after every PME certificate the Railway drivers can continue as loco running staff. In addition to this, the Railway driver working on high speed train must have to pass super-Psycho test at RDSO LUCKNOW. As well as loco running staff may also send for special medical examination and called anytime to the divisional office for Psycho test (Singh Ravi Kant, 2008).

4.1.5 Training Schedule \& Nature of Training After recruitment as an Assistant loco pilot, send to Zonal Training Centre for training. The training schedule is for 12 months on Diesel / Electric locomotive including technical education of locomotive, operational education of locomotive. In addition to this general and subsidiary rules training given. And after successful completion of training from ZTC trainees sent to posted division for practical training under Divisional Training Centre under Loco Supervisor. And after successful completion of training, posted as Assistant Loco Pilot (Singh Ravi Kant, 2008).

\section{Railway Driver Career Prospects}

A Railway driver usually begins his career as a diesel or electric assistant driver, where his job is mainly to check the state of the locomotive, help with all the auxiliary equipment as needed, and to call out the aspects of the signals. ALP with minimum 2 years of service as Diesel Asstt. /Electric Asstt. and 60,000 Kilometer running experience is required for the promotion to the post of Loco-Pilot (Goods). An assistant driver works as an assistant on goods trains, then on passenger trains, and finally on express trains. It takes at least 8 or 10 years, usually more, before an assistant driver works up the ranks to become the driver for a Rajdhani or Shatabdi train (www.Indian Railway Driver Information, 2012).

\section{Working Conditions}

I. For Railways' drivers operating on long distance routes, overnight stays in various locations will be necessary. Furthermore, it can be stressful, as delays and hazards on the track are not uncommon (Singh Ravi Kant, 2008).

II. His cab of the train should be relatively comfortable but it may be quite cold, hot and noisy (Singh Ravi Kant, 2008). 
III. At present Loco Pilots are classified under 'continuous' roaster. Not any calendar day rest provision. Normally the Loco Pilot has to work for 10 hours duty at a stretch and can demand relief after 12 hours with 2 hours prior notice to controller (Singh Ravi Kant, 2008). (ILO regulation only 9 hrs upper limit +1 hrs extra in case of emergency duty) (FIRE Quartly Magazine, Aug.2012).

IV. There are no fix schedules during operating Goods train. It takes normally long duty hours (sometimes continues 10 hours or more). While operating Goods train, very long waiting time for returning his own H.Q./Home Station (It is sometimes 30 hours or more). Loco-Pilot must be waited for the train at the time of returning to his H.Q./Home Station. After 96 hours of Sign-Off Loco-Pilot demand the compulsory returning for his H.Q. with driving train or without driving train. There are no immediate returning schedules of loco-pilot. In any personal or family emergency loco-pilot can't leave the cab without SignOff. In any emergency loco-pilot called for duty at any time while he is in rest periods.

\section{Periodic Rest to Loco-Pilots}

I. At least 5 periods of rest of not less than 22 consecutive hours each per month or at least 4 periods of rest of not less than 30 consecutive hours each per month each including a full night shall be given to Running Staff.

II. Hours of work for this purpose shall be calculated from 'signing on' to 'signing off'.

III. Periodic rest shall be given at headquarters.

IV. As far as possible it should be given once in 10 days.

Rest after duty: Based on total duty 'signing on' to 'signing off' rest after duty shall be given as follows:

\begin{tabular}{|l|l|}
\hline At headquarters : & \\
\hline For duty of less than 8 hours & 12 hours \\
\hline For duty of 8 hours or more & 16 hours \\
\hline
\end{tabular}

In either case a Running staff shall not be called to go out if rest is under 6 hours except in unavoidable necessity as in case of accidents or breakdowns.

\section{At outstation :}

8 hours rest for 8 hours running duty or more (staff may sign for rest to the extent of 6 hours if they so desire)

Interval between trips shall be considered as duty if it is equal to or less than 1 hour plus time allowed for train or engine attendance before and after trips.

* After 3 continuous full night duty, one full night rest/sleep provided (But practically it is not possible because Full night duty/running considered between 22:00 PM to 06:00 AM completely).

* Maximum duty hours in anyone trip should not exceed 10 hours (ILO regulation only 9 hrs upper limit $+1 \mathrm{hrs}$ extra in case of emergency duty) (FIRE Quartly Magazine, Aug.2012).

* Avg. duty hours in a fortnight (Period of two weeks) should not exceed 104 hours.

\section{Minimum home station rest should be:}

\begin{tabular}{|l|l|}
\hline If duty performed in the last trip is less than $8 \mathrm{hrs}$ & Rest of $12 \mathrm{hrs}$ \\
\hline If duty is $8 \mathrm{hrs}$. or more & Rest of $16 \mathrm{hrs}$ \\
\hline
\end{tabular}

But, Loco-Pilots cannot leave the H.Q. If, Loco Pilot wants to leave the head quarter, he must be given written application to the Crew-Controller. It means in emergency loco pilot called for duty in any time even in rest conditions.

* Full night considered between 22:00 PM to 06:00 AM.

* Duty hours counted from Sign-On (station where assigning duty/starting duty) to Sign-Off (station where completed duty/ leave duty).

* Loco-Pilots must be Sign-On his duty 30 minutes before the actual departure time of the train (HOER,

* Hours of Employment and Period of Rest rules 2005). 


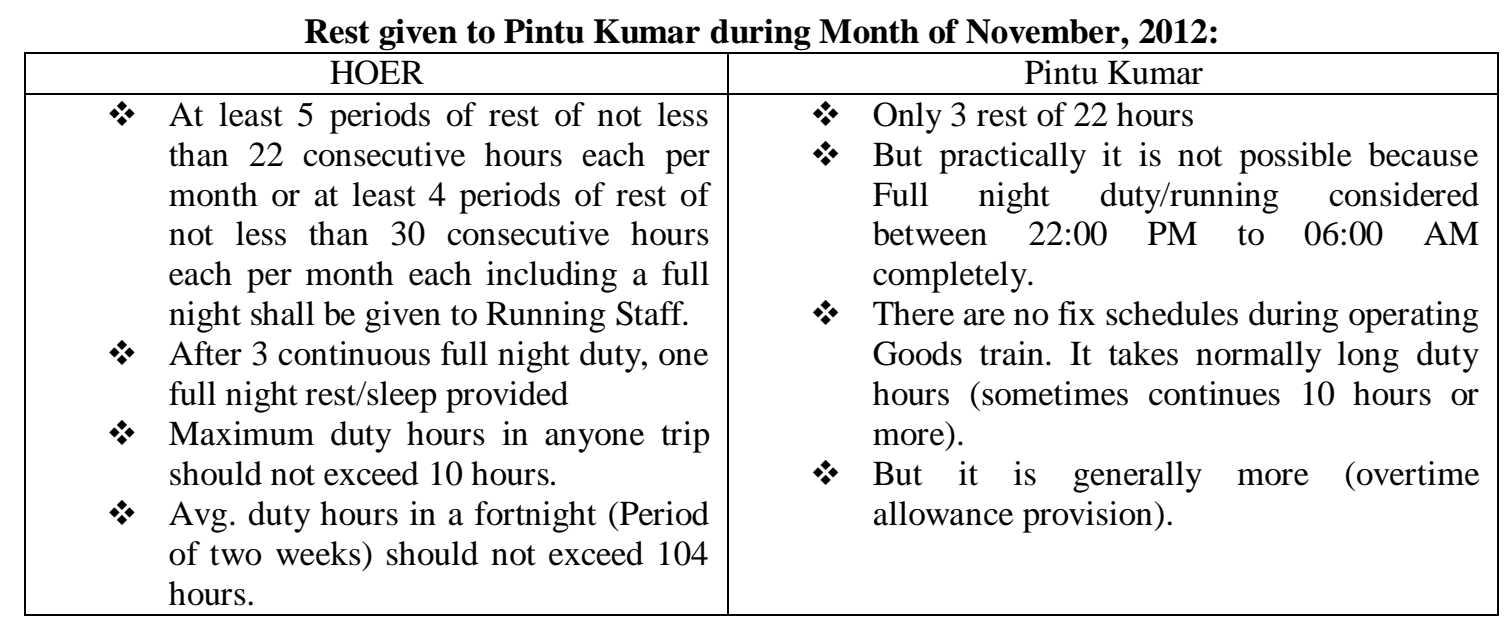

\section{Cab Conditions}

The heavy noise, dust pollution, excess heat, high voltage electricity in the electric locomotive and diesel smell in the diesel locomotive are contributing to early fatigue to the crew. The noise level in a diesel locomotive is about more than 100 decibels which is 25 decibels more than maximum allowed limit of 75 decibels by the Industrial Pollution Control Board. The heat, diesel smell, noise from the engine room comes to the driving cab as the doors in the driving cab are not designed sound proof. To overcome this problem the locomotive cab has to be air-conditioned so that fatigue will no attack the drivers and they can concentrate on their duties properly and ensure safety of trains. (FIRE Quartly Magazine, Aug.2012).

I. Noise level - More than 100 Desibal (it has an adverse impact on the minds of drivers. it is a source of disturbance to the drivers and does not allow them to work with concentration. Therefore, it is essential to keep noise under control, limited to 75 db by Industrial Pollution Control Board (fire Quartly magazine, aug.2012).

II. Temperature - Due to heavy night duty feeing cold or rain or hot sun in summer when normal temperature up to 46 to 48 degree, in locomotive, temperature increases up to temperature 54 to 56 degree centigrade, i.e. adverse weather conditions. Comfortable Room Temp. considered 25 degree centigrade (Singh Ravi Kant, 2008). Drivers efficiency is bound to suffer if the temp. of cab is either too low or too high(FIRE Quartly Magazine, Aug.2012).

III. Pollution and high voltage electricity. It has an adverse impact on the physical and mental health of drivers.

IV. Bad wiper, not properly functioning during rainy and foggy season, so poor visibility during raining and foggy.

V. No voice recorders in the cab for recording the shortcomings and calling out of signals (just like black box in flights).

VI. Loco-Pilot seat quality poor (normally without back rest provision).

VII. No natural calls facilities (no toilets available).

VIII. Sometimes After repairing chairs are in bad conditions, fan and lights are not properly working. It means there are no more/sufficient spare parts available.

IX. Poor lighting (without proper lighting, eye damage will occurs. it is essential to the health, safety and efficiency of drivers).

X. Commonly no air-conditioning.

XI. In diesel locomotive, seat position is very bad. Track not seen properly while loco pilot seated. Therefore he performs his duty always in standing position.

(Singh Ravi Kant, 2008).

\section{Running Room}

In running room, normally dormitory so loco pilots getting disturbance of sleep when other crew members or call boy are coming or getting ready for duty and putting lights etc. Due to high temp. Loco-Pilots not enjoyed fully undisturbed sleep before running trains. Because, generally no air-conditioning provided (FIRE Quartly Magazine, Aug.2012).

I. He carry himself rations, vegetables etc. for cooking meals in the kitchen of running room. Because in running room no any cooked food served around the clock. Only cooks are available for preparing the food. Due to shortage of cooking staff(generally 2-3 staff working) in running room, sometime cook 
taking 3-4 hours for preparing food (rules to served within 45 minutes). So They are unable to get more than 10-12 hours of rest even as they are provided $16 \mathrm{hrs}$. rest.

II. Commonly dormitory, due to this sleep disturbed.

III. Some places two-bedded room without attached toilet and bathrooms.

IV. Common toilets and bathrooms.

V. Unhighgenic water and meal atmosphere.

\section{X. $\quad$ Residence/Staff-Quarters}

I. $100 \%$ housing should not be provided to drivers as they are residing up to 5-6 KMs. away from their station of posting and are taking a lot of time in commuting. They are unable to get more than 10-12 hours of rest even at home station when they are provided $16 \mathrm{hrs}$. rest (FIRE Quartly Magazine, Aug.2012).

II. Railway drivers are living in rented/private houses and facing lot of problems for Sign-On and after SignOff their duty.

III. Some places quarters are situated very long distance (around 3 to $4 \mathrm{KM}$ ) away from his duty stations.

IV. There is no official vehicle provided by IR for Railway drivers.

V. Due to long distance of quarters, journey time increases for joining his duty.

VI. During odd weather and odd timing, very rigorous to join the duty and returned after the duty.

\section{Medical Facilities}

Paternity leave for 15 days only two times during the whole service periods. Paternity Leave may not normally be refused. Leave cannot be sanctioned for more than 5 years continuous.

Medical leave : - During one year,

* 10 days with full pay.

* 20 days with half pay.

* More than 20 days without pay.

When Railways' drivers joining after six months of medical leave, Railways' authority take a full/complete medical test. If found medically not fit, duty/job/post of Loco-Pilot can be changed. (Indian Railway Establishment code, Vol-1)

Reimbursement of Medical Expenses: When an employee or family members are referred to a hospital by Railway Medical Authority expenses incurred are reimbursed on production of bills/receipts countersigned by Supt. of the hospital.

For emergency Treatment without proper reference by ADMO

* In case of Government hospitals, full powers for reimbursement.

- In case of recognized hospitals/dispensary run by philanthropic organizations Up to Rs.2,00,000

* These powers will be exercised by GM/AGM duly scrutinized by FA\&CAO.

* Claims of higher amount will be referred to Railway Board.

- DRMs can reimburse claims up to Rs.10, 000 per case with a ceiling limit of Rs.2, 00,000 per year In case of Government/recognized hospitals only.

(Indian Railway Establishment Manual, Vol-1).

\subsection{Critical Duty}

XII. . Nature of Duty

12.1.1 When loco pilot working on high speed train, he have to work for 400 to $500 \mathrm{~km}$ at a stretch without any halt. During the run he cannot even release his urinal pressure. In NAGPUR DIVISION, when loco pilots booked to work RAJDHANI EXPRESS ex Nagpur to Bhopal, there are 265 signals and the running time given is 330 minutes. It means averagely after every 1 minute \& 22 seconds loco pilots must ready to observe signal. There are 296 gates (manned/ unmanned) in the same section. It means after every 1 minutes $\& 11$ seconds loco pilot must be prepared to observe gates condition. In addition to this loco pilot must also observe self train track, over head equipments as well as adjacent track and check the train if passing on adjacent track. He must also sharp attention on his locomotive performance. Loco pilot must take learning of road and signals with their proper locations, stations halts, level crossing gates (signaled and non- signaled gates, manned or unmanned gates) (Singh Ravi Kant, 2008).

12.1.2 Following signals (Averagely there are signals after every 1.5 Kilometer distance and gates averagely after every $1.3 \mathrm{~km}$ ) (Singh Ravi Kant, 2008). If he ignores any red signal and crossed it (while any accidents occurred or not), Railway takes very strict action against him normally removal from service. 
12.1.3 Highly appreciable role of Railway drivers is the only who works with full honesty, in day \& night, in heavy cold, hot $\&$ Rainy weather (www.indian railway driver information, 2012).

12.1.4 Loco pilot must have sharp look out. While on run he must observe all permanent \& temporary speed restrictions.

12.1.5 Continuous running for long hours. For example, Bihar Sampark Kranti Exp. (12565) runs between Darbhanga (Bihar) to New Delhi. Loco-pilot booked/sign-on his duty in Darbhanga and continuous running the train to Chhapra (That is around 202KM) and take around 5 hours continuous running /duty. And some other trains take around 5 to 6 hours for this distance.

12.1.6 There is no upper limit in the railways rulebook on the number of night duties to be done by the railways' driver. Despite data from major rail accidents, pointed to the fact that most mishaps take place between early night and late morning. The weekly rest provisions for Railways' drivers are vague. Faced with a severe staff shortage(now 60,000 loco drivers and there is $20 \%$ vacancy in the 82,000 sanctioned posts), coupled with the fact that most trains run also during night hours, railways is being forced to put most of its drivers on night duty for long periods. (www.indian railway driver information, 2012)

12.1.7 For instance, the Railways' driver roster for Hampi Express which collided with a stationary train suggests that the driver had run 23 trains in 19 days of which 12 were full-night, three half-night and seven full-day duties. This means the driver had undisturbed sleep in only seven days in the past three weeks. They (Railways' Drivers) are not allowed to break for food, refreshment or answer nature's call during duty hours. Duty of loco pilots is very much strenuous (www.indian railway driver information, 2012).

12.1.8 While operating diesel locomotives, they perform his duty in always standing position, because visibility effected due to bad seat position. Track not seen properly in seating conditions.

Due to high speed and continuous running train Loco-Pilots are extremely tired. Their eyes and Heart are more affected.

12.2 Routine Duty

12.2.1 Before starting the train/locomotive read safety circulars, safety bulletin, technical circulars, driver instruction, caution order, and divisional circulars.

12.2.2 Before starting the train/locomotive read the caution order carefully in which sectional track work progress with temporary speed restriction is mention.

12.2.3 Before starting the train/locomotive check the repair book of loco about any remark for any locomotive trouble.

12.2.4 Before starting the train/locomotive check the oil level (diesel, lube oil, compressor oil in case of diesel locomotive and transformer oil, GR oil, compressor oil, exhauster oil in case of electric locomotive) and time to time during the run (One time during about 100 kilometers, it depends on drivers' mind).

12.2.5 After coupling with the train check brake pipe pressure continuity test with guard.

12.2.6 After getting departure signal, loco pilot must start the train and run the train as per the aspect of station signals.

12.2.7 Stopping the train at the appropriate stops on each schedule.

12.2.8 Keeping a record of any Problems.

(Singh Ravi Kant, 2008).

\section{Life after the Duty/job}

When railway drivers at outstation duty, after signing off his duty, railway driver stay in the running room located near by the station premises. He carry himself rations, vegetables etc. for cooking meals in the kitchen of running room. Because in running room no any cooked food served around the clock. Only cooks are available for preparing the food. Due to shortage of cooking staff(generally 2-3 staff working) in running room, sometime cook taking 3-4 hours for preparing food (rules to served within $\mathbf{4 5}$ minutes). So, they are unable to get more than 10-12 hours of rest even as they are provided $16 \mathrm{hrs}$. rest. After the meal normally he goes to sleep immediately, because due to high speed and continuous running train Loco-Pilots are extremely tired.

Relatively same conditions at home station. $100 \%$ housing should not be provided to drivers as they are residing up to 5-6 KMs. away from their station of posting and are taking a lot of time in commuting. They are unable to get more than 10-12 hours of rest even at home station when they are provided 16 hrs. rest (FIRE Quartly Magazine, Aug.2012). After the meal normally he goes to sleep immediately, because due to high speed and continuous running train Loco-Pilots are extremely tired. 


\section{Personal/Family Related Problem}

He shares one very personal incidents of his life with me. He is married and father of two sweet children. At the time of his first child's birth, he was on his duty and suddenly he receive a call from his wife and his wife said you returned immediately because I am very serious and immediately required medical attention. But, at that time he was on his duty and not to leave the train and not possible to return back for home and admitted his wife in hospital. So, his neighbors were admitted his wife in a hospital and his wife delivered a child in the absence of him (her husband). He came back after about 12 hours and meets his wife and new born his child. And he says, these kinds of issues are still continuing. He is not giving (spending) more (sufficient) time with his family and societal activities.

* $100 \%$ housing should not be provided to drivers as they are residing up to 5-6 kms. away from their station of posting and are taking a lot of time in commuting. They are unable to get more than 10-12 hours of rest even at home station when they are provided $16 \mathrm{hrs}$. rest.

- All other railway employees get 12 National Holydays and 52 Sundays, guaranteed weekly rest but LocoPilot does not get any National Holyday. So, all the personal work has to be done by availing leave, or between short spells in between duties, which creates mental agony, losing concentration in running duties.

* No any calendar day rest provision, so that they may fulfill their family and social obligations.

(FIRE Quartly Magazine, Aug.2012).

I. Irregularities in lunch and dinner

XV. . Issues

II. Irregularities in sleep

III. Disturbed sleep

IV. Sleep disorder

V. Work under pollution and high voltage electricity

VI. Due to heavy night duty feeling cold or rain or hot sun in summer when normal temperature up to 46 to 48 degree, in locomotive, temperature increases up to temperature 54 to 56 degree centigrade, i.e. adverse weather conditions.

VII. Noise level more than $100 \mathrm{db}$

VIII. Insufficient facilities in running room

IX. Unhighgenic water and meal atmosphere

X. Suffer from stress related disease (hypertension, diabetes, frequent headaches etc.)

XI. No any calendar day rest provision, so that they may fulfill their family and social obligations.

XII. All their personal work has to be done by availing leave, or between short spells in between duties, which creates mental agony, losing concentration in running duties (FIRE Quartly Magazine, Aug.2012)

XIII. Do not spend sufficient time daily with his family members (including wife, child/children, and older parents).

XIV. Always miss out quality time with his family and friends because of nature of work.

\section{Status Report}

Based on above discussion, I felt work-life balance of Pintu Kumar as a railway driver in India is not very good. Indian Railways' trying to solve these serious issues, but it is still continuing and more effort needed. Work life-balance of Pintu Kumar as a railway driver is most important for the safe journey of passengers. So that, crores of passengers reach their destination safely.

\section{References}

[1]. Amitabh (2006),"Rail Accidents due to Human Errors-Indian Railways Experience" Ministry of Railways, Govt. of India.

[2]. "Allotment of Railway Quarters and Retention thereof”, Railway Board Letter No: E [G] 2006/QR1-6, dated: 20/04/2007, RBE No: $35 / 200$.

[3]. FIRE Quartly Magazine (Aug.2012), All India Loco Running Staff Association.

[4]. Govt. of India, Ministry of Railways, “Indian Railways Corporate Safety Plan" (2003-13), August 2003.

[5]. HOER (Hours of Employment and Period of Rest rules 2005)

[6]. Indian Railway Establishment Manual (Vol.-I), Chapter -I, Sec.-B, Sub.Sec I, II, \&III

[7]. India Railway Manual of AC Traction (Vol-3), Ch. - VI- Operation of Locomotive.

[8]. Indian Railway Establishment Manual (Vol-1); Chapter-XIII, Reimbursement of Medical Expenses Rule.

[9]. Indian Railway Establishment code (Vol-1), Master circular No. 25, "Absorption of Medically De-categorized Non-gazetted Staff in Alternative Jobs".

[10]. "Promotion of non-gazetted staff in loco running cadre - posts of Goods Driver redesignated as Loco Pilots [Goods]",( RBE No: 101/08, 12/09/2008,)

[11]. Sharma P.C \& Amitabh (2004), "Safety as Key Business Theme! -Indian Railways Perspective”, International Railway Safety Conference, Perth, Australia. 
[12]. Singh Ravi Kant, (2008) “Life of an Assistant Loco Pilot (ALP)/Assistant Driver”, All India Loco Running Staff Association (Posted on Web).

[13]. Govt. of India, Ministry of Railways, White Paper-Safety on Indian Railways, April 2003.

[14]. www.indian railway driver information, 2012, "Railway Driver-How to become a railway driver".

[15]. www.Indian railwas, Wikipedia

[16]. Indian Railways Online Official site (www.indian railway information.gov.in).

[17]. www.indian railway.gov.in 